\title{
Issues and development plan for Korea Water Cluster
}

\author{
Sung-woo Choi ${ }^{1}$, Hun-Kyun Bae ${ }^{2^{+}}$ \\ ${ }^{1}$ Department of Environmental Science, School of Environment, Keimyung University, Daegu 42601, Republic of Korea \\ ${ }^{2}$ Department of Global Environment, School of Environment, Keimyung University, Daegu 42601, Republic of Korea
}

\begin{abstract}
The Korean Ministry of Environment and Daegu Metropolitan City are establishing the Korea Water Cluster, which will focus on promoting and escalating Korean water industries. The water industry, a future-oriented and promising business sector, is continuously growing each year worldwide, so the project is very timely. In reality, however, challenges still need to be addressed, such as accessibility, logistics systems, social infrastructures, and attracting good companies. For the Korea Water Cluster to be successful, those issues should be solved, but it is difficult to untangle the matters only with efforts of the Korean Ministry of Environment and Daegu Metropolitan City since some issues will require a great deal of both money and time. Therefore, it is important for the Korean federal government to administer support and finances for certain parts of the project, and for the Korean Ministry of Environment and Daegu Metropolitan City to take on other issues to ensure the Korea Water Cluster is successful long-term. The success of the Korea Water Cluster project will result in the Korea Water Cluster becoming a global hub for the future water industries.
\end{abstract}

Keywords: Accessibility, Business attraction, Korea Water Cluster, Logistics system, Social infrastructure, Water industry

\section{Introduction}

The water industry covers the entire businesses associated to value creation with water supply such as intake, purification, distribution, etc. The water industry is classified into several sectors:

A. Water use sector (i.e. living, agricultural and industrial use)

B. Wastewater sector (i.e. wastewater treatment, reuse, energy recovery, etc.)

C. Equipment and device sector (i.e. sensor, pump, valve, analysis equipment, etc.)

D. Engineering and consulting sector

E. Plant operating and service sector

F. R\&D and education sector [1-3]

The global water industry market has been growing each year and its annual growth rate is $3.9 \%$. The growth rates of water industry in China and in several other South Asian countries have exceeded more than $10 \%$, meaning the largest investment market in the world over the next $20 \mathrm{y}$ will be the water industry. In this respect, the Korean water industry must become internationally competitive in order to share in the global water industry growth. Currently, the level of the high-technology sector associated with the Korean water industry is only $60 \%$ of that when compared to world class companies while level of water treatment skills and desalination technologies within the Korean water industry reach $70-80 \%$ of world class companies. Intensive investments should be made to improve the levels of the Korean water industry [4-7]. The Korean Ministry of Environment and Daegu Metropolitan City are establishing the Korea Water Cluster (KWC) located within Daegu Metropolitan City with a three-year construction period (2015-2017) and a budget of approximately 300 million USD. KWC consists of three major divisions - industrial complex, test-bed, and supporting facilities. The cluster will focus on promoting and escalating water business to raise the national competitiveness of the Korean water industry. Great parts of Korean water industries are still belonging to public sector, but privatization of water industry has been actively discussed to improve its performance, i.e. privatization of water industry in the UK during late 1990s and early 2000s [8-10] and other developed countries such as USA, Australia, Italy [11-14]. In this respect, KWC will vitalize private sectors of Korean water industry and play a pivotal role in future of the Korean water industry in terms of technology development and overseas expansion. Challenges such as accessibility, logistics systems, social infra-
This is an Open Access article distributed under the terms of the Creative Commons Attribution Non-Commercial License (http://creativecommons.org/licenses/by-nc/3.0/) which permits unrestricted non-commercial use, distribution, and reproduction in any medium, provided the original work is properly cited.
Received March 21, 2016 Accepted November 14, 2016

${ }^{\dagger}$ Corresponding author

Email: hunkyunbae@kmu.ac.kr

Tel: +82-53-580-5939 Fax: +82-53-580-5385

Copyright (C) 2017 Korean Society of Environmental Engineers 
structures, and attracting good companies need to be addressed since KWC is located in the outer part of Daegu Metropolitan City. The aim of this study is to address issues facing KWC and recognize the limitations that may hamper the success of KWC.

\section{Status of Current Water Industry}

According to GWI report [15], the capital expenditure on water infrastructure will grow by $4.9 \%$ in 2013 up from 3.7\% in 2012 and the global water equipment market will be up to 655 billion dollars. The world water market will grow to a size of about 6,700 billion dollars in 2018 if the water market were maintained annual growth rate, 3.9\% [16]. The growth pattern of world water industry would expect to continue its growth rate since the world experiences severe water shortages and water pollutions.

The size of the Korean water industry market was approximately 10 billion dollars in 2010, the 11th largest water market in the world, and is projected to grow rapidly up to 17 billion dollars in 2020 since the Korean government has strongly invested in this field and many private companies are active in this area [17]. The scale of the Korean water industry for overseas expansion is 3.7 billion USD between 1965 and 2010. The main issue the Korean water industry for overseas expansion faces is that the market is currently only oriented to desalination facility construction in Middle East [16]. Therefore, the Korean water industry should focus on future-oriented areas such as R\&D, services in operating and managing water treatment facilities, material and equipment developments, etc. to enhance its international competitiveness. World leading water companies such as Veolia, Suez, and GE Water concentrate their businesses towards service-based projects including operating and managing wastewater treatment facilities, developing materials for membrane filters, emerging new technologies for water treatments, and more. Those global water companies occupied $73 \%$ of the world water market in 2005 and many countries are supporting their own water companies in order to be internationally competitive. Because of this, Korean water companies should expand their businesses to compete worldwide in various fields within the water industry, rather than remain solely focused on one particular sector within specific regions.

\section{Korea Water Cluster (KWC)}

KWC is being established in the national industrial complex, located southwest of Daegu Metropolitan City (total area 645,000 $\mathrm{m}^{2}$ ), with an investment of approximately 300 million US dollars' budget (Fig. 1). The construction period for KWC is expected to take three years, from 2015 to 2017 . KWC will be consist of three major sectors: A water industry supporting facility $(65,000$ $\left.\mathrm{m}^{2}\right)$, a test-bed $\left(100,000 \mathrm{~m}^{2}\right)$, and a water industrial complex $\left(480,000 \mathrm{~m}^{2}\right)$. These facilities are working closely with one another. In other words, companies in the water industrial complex could have practical applications for their developed technologies using the test-bed in KWC in addition to assistance by the water industry supporting facility for their new technology developments, experiments, education, and business.

\subsection{Water Industry Supporting Facility}

The Water Industry Supporting Facility will consist of four systems: A Water Industry Agency, a Research Center, a Water Campus, and a Global Business Center to support developing water-related technologies and accelerating water businesses. The Water Industry Agency is the control tower for managing all cluster systems such as R\&D, education, facility maintenance, etc. The Research Center will be composed of a public laboratory as well as private enterprise laboratories. In addition, water-related private institutes, permission agencies, and certification authorities will be invited in this center. The main task of the Research Center is to assist developing water-related new technologies and to complement the test-bed as well as the water campus in KWC. The Water Campus will primarily focus on educating and promoting water-related professionals. The curriculum, of the Water Campus will concentrate on field works and new technology developments. The Water Campus will offer diverse educational experiences, degree and non-degree programs. The degree program will have graduate courses for those pursuing a Master's degree or Ph.D. and the non-degree programs are going to offer certificate and/or license courses, job training, compulsory education, etc. Facilities for the Water Campus will include classrooms and laboratories, a new-business supporting office, a student council room and other amenities. The Global Business Center will assist all companies in the Industrial Complex at KWC to build networks with other companies assisting in business development, advertising and exhibiting companies, and exchanging information. The Global Business Center will provide a venue for water-related international meetings, seminars, and conferences. Facilities for the Global Business Center include an exhibition hall, meeting rooms, conferences rooms, a lounge, and a guesthouse.

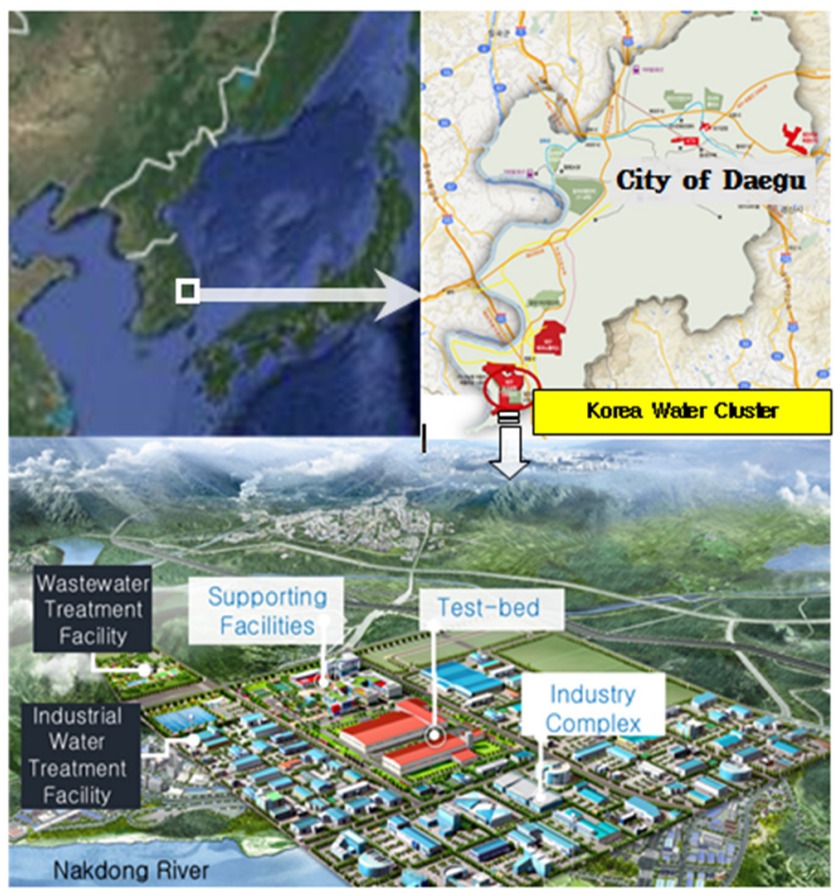

Fig. 1. Location and airscape of KWC. 


\subsection{Test-bed}

The test-bed in KWC will be a platform for conducting rigorous, clear, and replicable tests of new water-related technologies under a controlled environment with real field conditions. During the process of developing new technologies by an enterprise, a discrepancy often occurs when the technologies are applied to the actual field, despite the fact that technologies performance has already been proven in laboratory or pilot scale. A test-bed is the necessary space required to solve those problems since it provides an actual scale experimental situations for the technologies developed in laboratory or pilot scales. The test-bed in KWC will be large enough to provide the actual environment size for resident companies in KWC, allowing them to commercialize their newly developed technologies and to test results from the test-bed in a real world setting.

The test-bed in KWC will have three major processes: Drinking water treatment, wastewater treatment, and wastewater reuse.

\subsection{Industrial Complex}

The industrial complex in KWC is the facility in which water enterprises will settle down and develop networks for their businesses. The area will be $480,000 \mathrm{~m}^{2}$ and the minimum size of land sale would be $5,000 \mathrm{~m}^{2}$ and maximum $66,000 \mathrm{~m}^{2}$, meaning seven to 90 companies could move into this complex. All water companies such as drinking water treatment, water supply equipment and material, wastewater treatment, sewer related equipment and material, sludge treatment, and sludge-recycling companies will be qualified to move in the complex. The industrial complex will provide networks among resident companies for their overseas expansion as well as technology developments.

\section{Issues on Korea Water Cluster}

KWC will upgrade Korean water industries by increasing international competitiveness of resident companies. However, there are several issues KWC faces when attempting to attract companies to KWC. Table 1 summarizes the advantages and disadvantages of KWC.

Table 1. Advantages and Disadvantages of KWC

\begin{tabular}{c|c}
\hline Advantages & Disadvantages \\
\hline Closed to other industrial complexes & Accessibility \\
Abundant R\&D facilities & Poor logistics systems \\
Low land sale price & Lack of infrastructures \\
\hline
\end{tabular}

\subsection{Advantage}

Water enterprises in KWC will have many advantages since they are supported by KWC multiple supporting systems including: The Water Industry Agency, a Research Center, a Water Campus, and a Test-bed. KWC also has cooperative works with other water companies in or close to KWC for new technological developments and commercialization. Nearly 1,800 water companies and more than 3,300 manufacturing companies as well as other companies related to water industry are located within 13 industrial complexes at Daegu Metropolitan City or other industrial complexes within a one-hour drive distance from Daegu Metropolitan City. (e.g. electronic industrial parks in city of Gumi, machinery and shipbuilding industrial complex in city of Masan and city of Changwon are all within one-hour of Daegu). Moreover, companies in KWC are ensuring high-quality human resources required for the water industry since about 50 R\&D centers and 53 universities and community colleges are located within or very near Daegu Metropolitan City. A low land sale price, $\$ 900.00$ per $3.3 \mathrm{~m}^{2}$, would be another benefit for resident companies in KWC.

\subsection{Disadvantage}

The biggest problem facing KWC is accessibility. The location of KWC is at the far southwestern edge of Daegu Metropolitan City, which takes one-and-a-half-hours drive from the downtown of Daegu and more than two hours' drive from East Daegu Station at which the Korean high-speed express train (KTX) stops. Therefore, it may take more than five hours of travel time if approaching from the Seoul area by KTX (depending on where one leaves from within Seoul). It may also take more time if someone approaches KWC using the Daegu International Airport, as the airport is located in northeastern Daegu. In addition to accessibility, logistics systems are another issue facing KWC. Daegu Metropolitan City is located inland, meaning there is no direct access to the sea. Furthermore, the freeway near KWC, Jungbu Naeryuk Freeway, has only two lanes in each direction. Limited logistical systems will be the one of main obstacles facing the KWC. The last issue for KWC is the lacking of social infrastructure such as housing, education, accommodation, and commercial areas. Most of regions close to KWC are adjacent to mountains and farmlands (Fig. 2), meaning close proximity social infrastructures for people working at KWC will be limited. Daegu Metropolitan City is planning a new town project which is currently constructing 10,000 household apartments as well as two public schools to make up for the lack of social infrastructures for KWC, but the project is not sufficient enough for all the people in KWC. Also, the new town project will not be completed before the construction of KWC is finished at end of 2017.

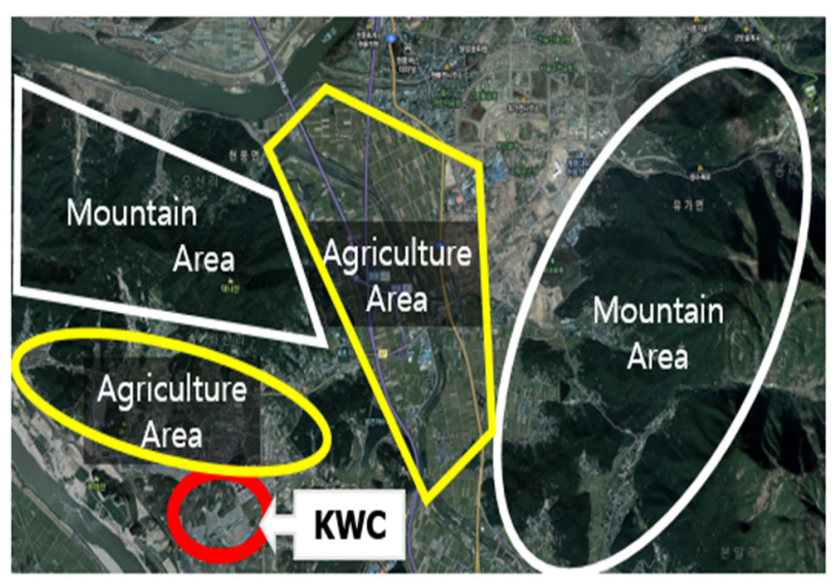

Fig. 2. Surrounding area of KWC. 


\section{Developing Plans for Korea Water Cluster}

Success and long-term growth of KWC will be dependent on solving the previously stated issues as well as its ability to attract innovative and competitive companies. Possible solutions are as follows.

\subsection{Improving Accessibility}

The first step for improving accessibility of KWC is utilizing the Daegu Metropolitan City subway systems to ease and quicken transport times. Subway Line No. 1 (Green line at Fig. 3) should be extended to KWC (Black line at Fig. 3). Currently, there is only one bus line to access KWC from the final stop of Daegu Subway Line No. 1 and it takes more than one hour for a one-way trip. People who take the KTX could reduce their travel time to visit KWC if Daegu Subway Line No. 1 is extended to the KWC location since a transfer is not needed and the subway is much quicker than taking a bus. The extended line will reduce travel time by about $50 \%$, or approximately 40 min from KWC to downtown Daegu and about one hour to East Daegu Station and/or the Daegu Airport. In addition to the extended line, a belt line (Red line at Fig. 3) which connects industrial complexes, residential areas, commercial areas, West Daegu Station, East Daegu Station, and Daegu Airport should be constructed. The belt line will allow companies in KWC easy access to other firms located in other industrial complexes in the Daegu area. Additionally, the belt line will provide an access to social infrastructures for people in KWC and this could make up for the lack of social infrastructures in KWC. The project, however, requires a huge investment, meaning both Daegu metropolitan city and the Korean national government need to approve and support the plan.

The second step is to build a West Daegu Station on the belt line in order to reduce the itinerant time when one visits KWC from other cities using the KTX. Approaching from a West Daegu

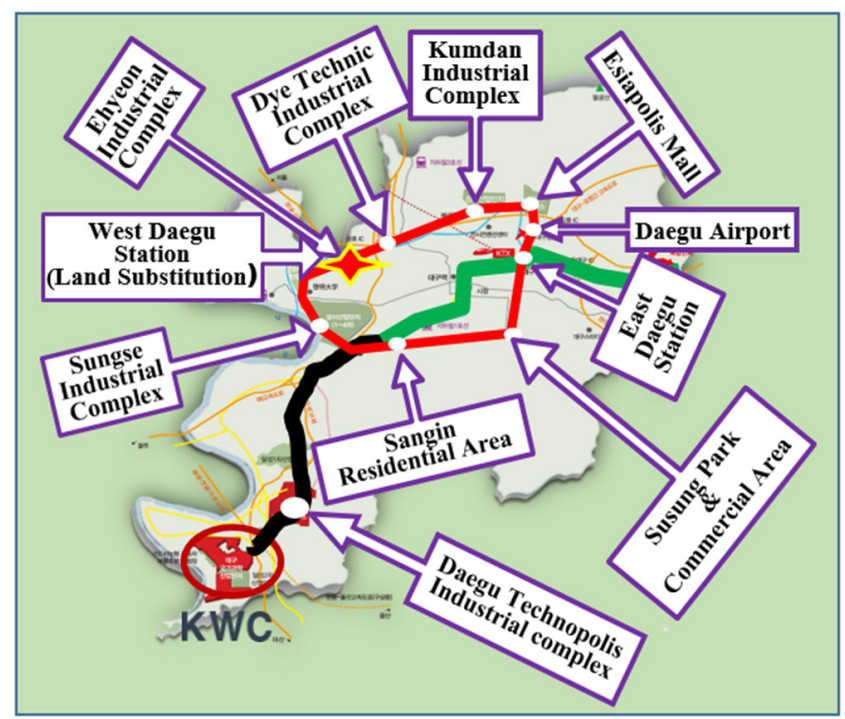

Fig. 3. Developed plan for access to KWC.
Station could save approximately one hour travel time to KWC considering the KWC is located in the southwest of Daegu Metropolitan City. The travel time gap between a West Daegu Station and East Daegu Station to KWC will be much greater if visiting KWC by car since traffic in Daegu Metropolitan City is often very heavy.

The last step will be to expand the Daegu Airport. Right now, it takes more than four hours if traveling to KWC via Incheon International Airport, the major international airport in Korea. A plan which could reduce the access time to KWC should be proposed for visitors from other countries. Currently, the Daegu Airport has a few international connections to Beijing and Shanghai, China, Osaka, Japan and Taipei, Taiwan, but those are not sufficient to stimulate internal activities for water business. In order to be more competitive, Daegu Airport needs connections to North America, Europe, and the Middle East, allowing water companies in KWC to quickly and easily access to other businesses globally.

\subsection{Improving Logistics Systems}

In order to improve logistics to KWC, connections to Seoul, Incheon, Busan and Changwon, which are logistics hub cities in Korea, need to be improved. Both the cities of Changwon and Busan are the main cities in Korea for international trade because of their international seaports. Both cities are located south of Daegu Metropolitan City, and both are within one to one and half hour driving distance, meaning KWC should focus on connections to those two cities in order to improve logistical systems for increased international trade. The main pathway between KWC and the cities of Changwon and Busan is the Jungbu Naeryuk Freeway (Fig. 4), but the Jungbu Naeryuk Freeway has only two lanes each direction, which limits logistics for KWC. The freeway should be widened to at least five lanes each way to improve efficiencies of logistical systems for KWC.

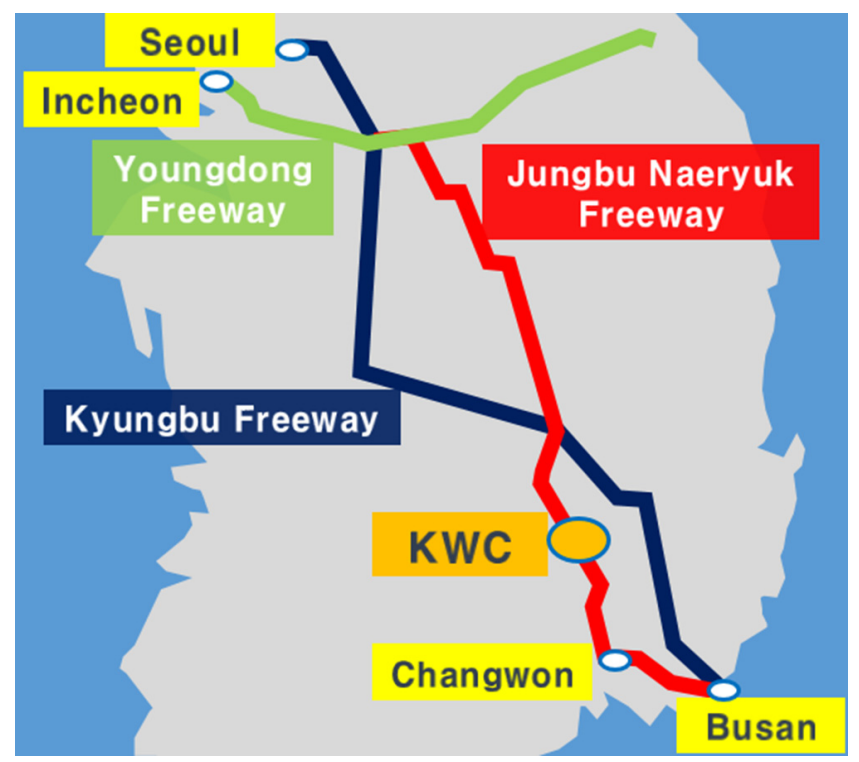

Fig. 4. Developed plan for logistics systems of KWC. 


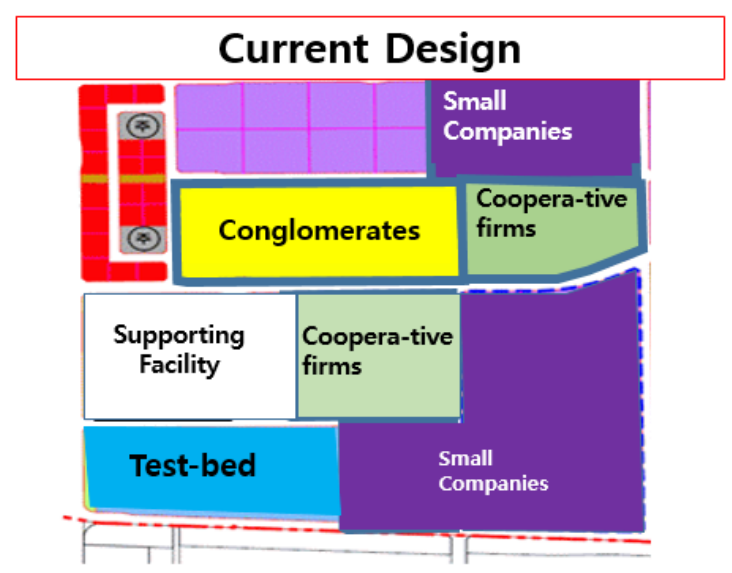

Fig. 5. Conglomerate-oriented design.

The City of Incheon has the primary and largest international airport in Korea and is also the main gate to China. Seoul Metropolitan City is not only the capital city, but the center of Korean economics as well. These two cities are also important to KWC for businesses conducted with China and for the domestic water business market. There are two additional freeways, Kyungbu Freeway and Youngdong Freeway, beside Jungbu Naeryuk Freeway, to get Incheon and Seoul from KWC. The Kyungbu Freeway and the Youngdong Freeway experience chronically heavy traffic, especially close to Seoul area often resulting in longer than usual four-hour travel time to KWC. Those two freeways must also be widened to reduce heavy traffic.

\subsection{Improving Social Infrastructure}

Currently, social infrastructures for KWC are poor since the surrounding area of KWC mostly consists of mountains and agricultural fields (Fig. 2). Daegu Metropolitan City is carrying forward a new town project, which is constructing apartments for 10,000 households and two public schools, in order to reduce the deficient of social infrastructures near KWC. Those facilities, however, cannot fully cover the shortage of social infrastructure near KWC since the national industry complex is also establishing within the same district as KWC.

To begin with, Daegu Metropolitan City should focus on accelerating the completion of the new town project so that the facilities can be provided as soon as possible, hopefully before the end of 2017, the time when construction for KWC is scheduled to be completed. Daegu Metropolitan City also needs to transfer their shares to people in KWC. Daegu Metropolitan City has 10\% of new houses constructed by Daegu Urban Development Corporation which could parcel out to people who work for small companies without lottery system. Daegu Metropolitan City should find a way to give their shares to people in KWC, i.e. a special law, no matter what they are working for small companies or not.

Secondly, the new project for additional housing and other social infrastructures should begin immediately. However, most territories around KWC are absolute farmland and/or development restricted areas, meaning construction for social infrastructure around KWC is not allowed at this moment. Daegu Metropolitan

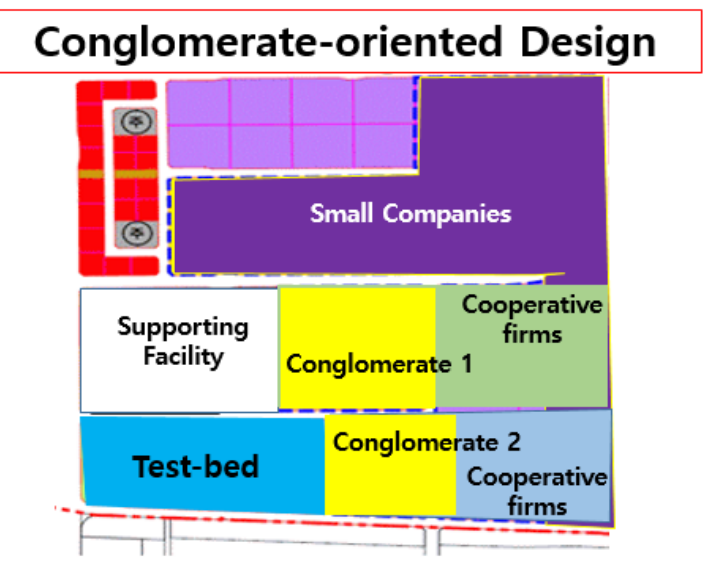

City should change the region to a special development area to secure space for constructing more facilities.

Lastly, some parts of the supporting facilities in KWC such as cafeteria, banks, and lounges should be open to the public until social infrastructures around KWC are sufficient for people in KWC and their families.

\subsection{Attracting Conglomerates and Excellent Firms}

Conglomerates will play an important role regarding long-term growth of KWC since they will have a great ripple effect on the Korean water industry. KWC, therefore, should offer various incentives toward conglomerates to persuade them to locate in the industrial complex at KWC. For example, in order to attract companies to their cities, Jeju Island provided huge spaces to Daum Communication Corp. with inexpensive land and the Gity of Ulsan paid the construction costs for SK Chemicals Co.

Expanding opportunities for various national projects as well as local government projects may be the biggest incentive to tenant companies in KWC. In other words, new technologies that are developed and tested at the test-bed in KWC by companies would have a priority to participate in projects, ordered by Korea Ministry of Environment, K-Water, Korea Environment Corporation, local governments, etc., without competition. Conglomerates should be also encouraged to establish a consortium with small companies in KWC, so that all benefits can be distributed to as many companies in KWC as possible. This will be another inducement for attracting excellent small firms. Whole plans can be achieved by legislating a special law for KWC.

The industrial complex in KWC should plan to maximize the efficiency for both conglomerates and cooperative firms throughout conglomerate-oriented designs (Fig. 5). For example, companies related to membrane filter, pump, pipe, sensors, etc. should locate close to 'water treatment facility' construction conglomerates. This plan makes the relationship between conglomerates and cooperative firms stronger and increases the efficiency of collaboration between conglomerates and cooperative firms. In addition, conglomerates should be located next to the test-bed and/or supporting facility in order to maximize convenience for communicating with KWC support systems. 
Financial support and tax credits are other ways to attract excellent enterprises to KWC. For instance, Daegu Metropolitan City arranges bank financing to excellent firms willing to move in KWC and the City will waive local taxes for certain periods to relieve firms' burden for moving and constructing their new facilities.

\subsection{High Value-added, Technology-intensive Industrial Complex}

A top priority of the industrial complex in KWC should go to high value-added, technology-intensive enterprises to ensure KWC's long-term growth. In reality, world class water business firms (i.e. Suez, Veolia, GE Water) are focusing on high value-added, technology-intensive areas like new technology development, water treatment facility operations, and material improvements. KWC, therefore, should concentrate on such high value-added, technology-intensive areas as well. Cases of successful high value-added, technology-intensive industrial parks include RTP (Research Triangle Park) in North Carolina, USA and the Water Council in Milwaukee, Wisconsin, USA. Low value-added, labor-intensive industries used to locate in North Carolina, but the state recruited high value-added, technology-intensive companies such as computer, network, medical, biochemical, and pharmaceutical firms throughout RTP and now the state has achieved significant progress. The City of Milwaukee, Wisconsin established the Water Council to concentrate on water business, water-related research, business, and education. Through the efforts of the Water Council, the City of Milwaukee is now the hub of the global water industry. KWC should follow these examples and invite high value-added, technology-intensive groups such as national labs, private research centers, and headquarters of water related corporations. So that KWC can achieve long-term development and be a hub of the water technology industry, particularly in Asia.

\section{Conclusions}

The global water industry is growing dramatically and will continue to do grow dramatically so long as extreme problems from climate change and water shortages are not solved. KWC, therefore, is a seasonable project and is expected to contribute greatly to the future and long-term development of the Korean water industry by increasing the international competitiveness of Korean water businesses. However, the KWC development still faces many challenges as mentioned in the paper. Plans presented in this paper for improving accessibility and logistical systems are massive construction and development projects, which require approval and funding from a national government level, while plans for social infrastructures and attracting excellent companies are the role of the Korean Ministry of Environment and Daegu Metropolitan City. Therefore, the Korean government should fully support the Korean Ministry of Environment and Daegu Metropolitan City to help solve the issues facing KWC. Also, the Korean Ministry of Environment and Daegu Metropolitan City must device plans to attract high value-added technology-intensive enterprises referring to RTP in North Carolina and the Water Council in Milwaukee models to make KWC a hub for the global water industry.

\section{Acknowledgments}

The study was funded by 2015 Daegu Green Environment Center's research funds. Authors would like to thank Prof. Andrew Turner at Keimyung University for his comments on this paper.

\section{References}

1. Choi ES. Water industry in Korea. J. Korean Soc. Civ. Eng. 2007;55:4-5.

2. Yim SK. Proposals for fostering water industry in the stand point of enterprises. J. Korean Soc. Civ. Eng. 2007;55:50-57.

3. Yun Z. Better regulations for Korean water industries. J. Korean Soc. Civ. Eng. 2007;55:40-49.

4. GWI (Global Water Intelligence). Overview of the global water market. A Global Water Intelligence Publication; 2014.

5. Lee WT. Development of Korea water industry throughout 2015 World Water Forum. Water for Future 2012;45:18-22.

6. Chung HJ. Thinking about establishing Water Business Cluster: Water Business Cluster, World Water Business Mecca. Water J. 2014;120:94-97.

7. Daegu Metropolitan City. Daegu water industry cluster composition scheme, and future plans for the leap into the industrial hub city. Material for Public Relations of Daegu Metropolitan City; 2015.

8. Ogden SG. Accounting for organizational performance: The construction of the customer in the privatized water industry. Account. Org. Soc. 1997;22:529-556.

9. Shaoul JA. Critical financial analysis of the performance of privatized industries: The case of the water industry in England and Wales. Crit. Perspect. Account. 1997;8:479-505.

10. Cubbin J. Efficiency in the water industry. Util. Policy 2005;13:289-293.

11. Kurland NB, Zell D. Water and business: A taxonomy and review of the research. Organ. Environ. 2010;23:316-353.

12. Torres M, Paul CJM. Driving forces for consolidation or fragmentation of the US water utility industry: A cost function approach with endogenous output. J. Urban Econ. 2006;59:104-120.

13. Abbott M, Cohen B. Productivity and efficiency in the water industry. Util. Policy 2009;17:233-244.

14. Antonioli B, Filippini M. The use of a variable cost function in the regulation of the Italian water industry. Util. Policy 2001;10:181-187.

15. GWI (Global Water Intelligence). Market Profile: The global water market. A bright new future for water? A Global Water Intelligence Publication; 2014.

16. Choi IH. Detailed plans for construction and operation of test-bed in Korea Water Cluster. Proceedings, Seminar for establishing Korea Water Cluster; 12 December 2014.

17. Daegu Techno Park Policy Planning Team. Plans for attracting leading water company on Korea Water Cluster. Research report. Daegu Metropolitan City; 2014. 